\title{
A practical approach to assess leg muscle oxygenation during ramp-incremental cycle ergometry in heart failure
}

\author{
A.C. Barroco ${ }^{1,3}$, P.A. Sperandio ${ }^{1,2,3}$, M. Reis ${ }^{4}$, D.R. Almeida ${ }^{1}$ and J.A. Neder ${ }^{5}$ \\ ${ }^{1}$ Disciplina de Cardiologia, Universidade Federal de São Paulo, São Paulo, SP, Brasil \\ ${ }^{2}$ Departamento de Cardiologia, Instituto Dante Pazzanese de Cardiologia, São Paulo, SP, Brasil \\ ${ }^{3}$ Setor de Fisiologia Clínica do Exercício, Disciplina de Pneumologia, Universidade Federal de São Paulo, São Paulo, SP, Brasil \\ ${ }^{4}$ Departamento de Fisioterapia, Faculdade de Medicina, Universidade Federal do Rio de Janeiro, Rio de Janeiro, RJ, Brasil \\ ${ }^{5}$ Laboratory of Clinical Exercise Physiology, Division of Respiratory and Critical Care Medicine, Queen's University, Kingston, ON, Canada
}

\begin{abstract}
Heart failure is characterized by the inability of the cardiovascular system to maintain oxygen $\left(\mathrm{O}_{2}\right)$ delivery (i.e., muscle blood flow in non-hypoxemic patients) to meet $\mathrm{O}_{2}$ demands. The resulting increase in fractional $\mathrm{O}_{2}$ extraction can be non-invasively tracked by deoxygenated hemoglobin concentration (deoxi-Hb) as measured by near-infrared spectroscopy (NIRS). We aimed to establish a simplified approach to extract deoxi-Hb-based indices of impaired muscle $\mathrm{O}_{2}$ delivery during rapidly-incrementing exercise in heart failure. We continuously probed the right vastus lateralis muscle with continuous-wave NIRS during a rampincremental cardiopulmonary exercise test in 10 patients (left ventricular ejection fraction $<35 \%$ ) and 10 age-matched healthy males. Deoxi-Hb is reported as \% of total response (onset to peak exercise) in relation to work rate. Patients showed lower maximum exercise capacity and $\mathrm{O}_{2}$ uptake-work rate than controls $(\mathrm{P}<0.05)$. The deoxi-Hb response profile as a function of work rate was S-shaped in all subjects, i.e., it presented three distinct phases. Increased muscle deoxygenation in patients compared to controls was demonstrated by: i) a steeper mid-exercise deoxi-Hb-work rate slope $(2.2 \pm 1.3 \mathrm{vs} 1.0 \pm 0.3 \%$ peak/W, respectively; $\mathrm{P}<0.05$ ), and ii) late-exercise increase in deoxi- $\mathrm{bb}$, which contrasted with stable or decreasing deoxi-Hb in all controls. Steeper deoxi-Hb-work rate slope was associated with lower peak work rate in patients $(r=-0.73 ; P=0.01)$. This simplified approach to deoxi-Hb interpretation might prove useful in clinical settings to quantify impairments in $\mathrm{O}_{2}$ delivery by NIRS during ramp-incremental exercise in individual heart failure patients.
\end{abstract}

Key words: Heart failure; Exercise; Oxygen; Muscle; Near-infrared spectroscopy

\section{Introduction}

Heart failure is a complex syndrome characterized by the inability of the cardiovascular system to maintain oxygen $\left(\mathrm{O}_{2}\right)$ delivery [i.e., muscle blood flow $\left(\dot{Q}_{m}\right)$ ] matched to metabolic demands (1). This is particularly true during dynamic exercise as the peripheral muscle requirements for $\mathrm{O}_{2}$ increase markedly $(2,3)$. In fact, there is wellestablished evidence that the deleterious bioenergetic consequences (e.g., early anaerobic metabolism) of impaired $\mathrm{O}_{2}$ availability are centrally related to patients' exercise intolerance (4). Selected pharmacological (e.g., sildenafil intake) and non-pharmacological therapies (i.e., physical training) have been found useful in improving $\mathrm{Q}_{\mathrm{m}}-\mathrm{O}_{2}$ uptake $\left(\mathrm{V}_{2}\right)$ matching with important beneficial consequences to patients functioning (5-7).

In this context, there is a widespread interest in noninvasive methods to detect impairments in exercise $\dot{\mathrm{Q}}_{\mathrm{m}}-\dot{\mathrm{V}} \mathrm{O}_{2}$ matching in heart failure patients (5). Near infrared spectroscopy (NIRS), in particular, is an optical method that allows transcutaneous monitoring of skeletal muscle deoxygenation (deoxi-Hb), an index of fractional $\mathrm{O}_{2}$ extraction $(8,9)$. It has been postulated that muscle deoxi-Hb can reflect dynamic abnormalities in $\dot{Q}_{m}-\dot{V} O_{2}$ coupling when the rate of increase in $\dot{\mathrm{V}}_{2}$ is constant, e.g., in response to a rapidlyincremental (ramp) exercise protocol. Thus, higher values and/or faster increases in deoxi-Hb would result from insufficient $\dot{\mathrm{Q}}_{\mathrm{m}}$ relative to $\dot{\mathrm{VO}}_{2}$ as muscle $\mathrm{O}_{2}$ extraction increases to compensate for insufficient $\mathrm{O}_{2}$ delivery $(4,10)$. Despite its potential clinical usefulness, this approach has been mostly used in healthy subjects (4). Moreover, the response profile has been described by complex non-linear mathematical models (either the hyperbolic or sigmoid functions) $(4,10)$. As pointed out by Spencer et al. (11),

Correspondence: P.A. Sperandio: <prissperandio@gmail.com> 
fitting the whole response in a single function has little physiological rationale and it might represent a "fit of convenience". Translating the deoxi-Hb signal to the clinical world using a practical and feasible approach remains an important gap to allow a wider use of NIRS for the functional assessment of heart failure patients.

This prospective study was designed to establish a novel, clinically-friendly approach to quantify $\dot{\mathrm{Q}}_{\mathrm{m}}-\dot{\mathrm{V}} \mathrm{O}_{2}$ mismatch by deoxi-Hb during ramp-incremental exercise in patients with heart failure. We specifically hypothesized that impairments in peripheral muscle $\mathrm{O}_{2}$ delivery would be indicated by steeper mid-exercise deoxi-Hb-work rate slope and/or greater increases in late-exercise deoxi-Hb in patients compared to healthy controls.

\section{Subjects and Methods}

\section{Subjects}

Ten non-smoking males from the heart failure outpatient clinic of the São Paulo Hospital (New York Heart Association functional score II and III) and 10 age- and gender-matched healthy controls were assessed. Patients presented with left ventricular ejection fraction (LVEF) $<35 \%$ according to $3-\mathrm{D}$ transthoracic echocardiogram. They were under optimal pharmacological treatment for stage "C" patients as established by the American Heart Association and American College of Cardiology guidelines (2). We excluded patients who had a history of recent disease decompensation (within 3 months), functional evidence of obstructive pulmonary disease (forced expiratory volume in $1 \mathrm{~s} /$ forced vital capacity $<0.7$ ), anemia (hemoglobin $<13 \mathrm{~g} / \mathrm{dL}$ ), exercise-induced asthma, diabetes mellitus or other metabolic disease, significant ventricular arrhythmia, atrial fibrillation, unstable angina, acute myocardial infarction in the preceding year, and peripheral arterial disease associated with intermittent claudication. No patient had been previously submitted to cardiovascular rehabilitation to avoid the influence of physical activity on muscle oxygenation (12).

Controls were office staff and non-medical employees from the Universidade Federal de São Paulo. They were required to be sedentary as indicated by lack of regular physical activity in the preceding 5 years. No control presented with a previous history of pulmonary, cardiovascular, autoimmune or metabolic diseases. Prior to study inclusion, the controls underwent clinical assessment, pulmonary function tests, blood analysis (including $\mathrm{Hb}$ ) and resting electrocardiogram and echocardiogram. The study protocol was approved by the Institutional Research Ethics Board and all participants gave written informed consent (Project \#0935/07).

\section{Measurements}

Cardiopulmonary exercise test. Cycle ergometer-based (Corival ${ }^{\circledR} 400$, Medical Graphics Corporation, MGC, USA) cardiopulmonary exercise test $\left(\mathrm{CardiO}_{2}\right.$ system, $\left.\mathrm{MGC}\right)$ was performed following a ramp-incremental protocol (5-10 W/min for patients and 5-20 W/min for controls). Subjects were asked to cycle at a frequency of $50 \pm 5 \mathrm{rpm}$. Peak $\dot{\mathrm{VO}}_{2}(\mathrm{~mL} / \mathrm{min})$ was the highest value obtained at exercise cessation: values were compared with those predicted by Neder and co-workers (13). Other measurements included: $\mathrm{CO}_{2}$ output $\left(\dot{\mathrm{V}} \mathrm{CO}_{2}, \mathrm{~mL} / \mathrm{min}\right), \mathrm{R}$ (respiratory exchange ratio), minute ventilation $(\dot{\mathrm{V}}, \mathrm{L} / \mathrm{min})$, respiratory rate $(f)$, ventilatory equivalents for $\mathrm{O}_{2}$ and $\mathrm{CO}_{2}\left(\dot{\mathrm{V} E} / \mathrm{NO}_{2}\right.$ e $\left.\dot{\mathrm{V} E} / \dot{\mathrm{V}} \mathrm{CO}_{2}\right)$ and end-tidal partial pressure of $\mathrm{O}_{2}$ and $\mathrm{CO}_{2}\left(\mathrm{P}_{\mathrm{ET}} \mathrm{O}_{2}\right.$ e $\left.\mathrm{P}_{\mathrm{ET}} \mathrm{CO}_{2}, \mathrm{mmHg}\right)$. Heart rate ( $\mathrm{HR}$, bpm) was determined using R-R distance as determined by a 12-lead electrocardiogram (CardioPerfect ${ }^{\mathrm{TM}}$, MGC). Oxygen saturation was determined by pulse oximetry $\left(\mathrm{SpO}_{2}\right.$, Onyx ${ }^{\mathrm{TM}}$, Nonim, USA). Patients were asked about their dyspnea and leg effort every 2 min according to the $0-10$ Borg scale. The $\mathrm{VO}_{2}$ at the lactate threshold was estimated by the gas exchange method (modified $V$-slope) and confirmed by the ventilatory method, i.e., $\dot{\mathrm{V} E} / \mathrm{VO}_{2}$ and $\mathrm{P}_{\mathrm{ET}} \mathrm{O}_{2}$ increase coupled with $\dot{\mathrm{VE}} / \dot{\mathrm{V}} \mathrm{CO}_{2}$ and $\mathrm{P}_{\mathrm{ET}} \mathrm{CO}_{2}$ stability.

\section{Peripheral muscle oxygenation}

Leg muscle deoxygenation was measured by the NIRO $200^{\circledR}$ system (Hamamatsu Photonics, Japan). The NIRS theory has been described elsewhere (9). Briefly, an optical fiber bundle carries the near-infrared light produced by a laser diode to the tissue while another optical fiber bundle captures the tissue-transmitted light to a photon detector in the spectrometer. The light intensity and the transmitted light is continuously recorded and, along with the relevant extinction coefficient, used to measure changes in the hemoglobin oxygenation level $(\mathrm{Hb})$ and myoglobin (Mb). The optodes (light emitting and photoreceptor sensors) were set at the vastus lateralis muscle of the left quadriceps, between the lateral epicondyle and greater trochanter of the femur, fixed with an appropriate adhesive tape and covered with a neoprene band to avoid light penetration.

The variables evaluated by NIRS were oxygenated and deoxygenated $\mathrm{Hb}$ concentrations (oxi-Hb and deoxi$\mathrm{Hb}$, respectively). From these primary signals, total $\mathrm{Hb}$ is derived, i.e., oxi-Hb + deoxi-Hb. Considering that about $70 \%$ of the $\mathrm{Hb}$ intramuscular signal comes from venous bed, variations in local blood volume (including venous) are expected to impact more oxi-Hb than deoxi-Hb (14-16). Thus, many laboratories have adopted deoxi-Hb as the preferred marker for changes in the $\mathrm{O}_{2}$ fractional extraction $(14,15,17)$, i.e., an index of $\dot{\mathrm{Q} m}-\dot{\mathrm{V}}_{2}$ (mis)match (18). The device used here (continuous wave NIRS) does not measure light tissue reflection and scattering (18); thus, values were recorded as a variation $(\Delta)$ from baseline in $\mathrm{mMol} / \mathrm{cm}$ and are reported as a percent of the end-test value, i.e., $0-100 \%$.

\section{Statistical analysis}

The statistical program used was SPSS ${ }^{\circledR}$ version 13.0 (SPSS ${ }^{\circledR}$, USA). Unless otherwise stated, data are reported 
as means and SD. Unpaired t-test (or Mann-Whitney test, when appropriated) was used for between-group comparisons. The slope of linear regression involving exercise deoxi-Hb as a function of work rate determined the rate of increase in the former variable. Pearson correlation was used to assess the level of linear association between continuous variables. The level of statistical significance was set at $<5 \%(\mathrm{P}<0.05)$ for all tests.

\section{Results}

There were no significant between-group differences in anthropometric attributes (Table 1). The main etiology of heart failure was non-ischemic cardiomyopathy and, as expected by the inclusion criteria, all patients showed severe left ventricular dysfunction. Peak work rate and peak $\dot{\mathrm{VO}}_{2}$ were markedly reduced in patients; for instance, 7 patients were on Weber's class $C$. Patients had shallower $\dot{\mathrm{VO}}_{2}$-work rate slopes than controls; conversely, $\dot{\mathrm{V}} \mathrm{E} \dot{\mathrm{V}} \mathrm{CO}_{2}$ was higher and $\mathrm{P}_{\mathrm{ET}} \mathrm{CO}_{2}$ lower in patients compared to controls $(P<0.05$; Table 1$)$.

As previously described in normal subjects $(4,10)$, deoxi-Hb response curve as a function of increasing work rate was S-shaped i.e., it resembled a sigmoid in all subjects. From the raw signal, we initially identified two inflection points: point "A" corresponded to the work rate after exercise onset at which deoxi-Hb started to systematically increase, and from point " $A$ " onward we applied linear regression to deoxi-Hb. Point " $B$ " corresponded to the work rate at which there was a systematic departure from linearity.

The range of work rates before point " $A$ ", between points " $A$ " and " $B$ " and after point " $B$ " up to peak exercise (point " $C$ ") were named phases " 1 ", " 2 " and " 3 ", respectively. In addition to the increase in slope $(S)$ of deoxi-Hb throughout phase 2 , we calculated the deoxi-Hb difference (" $\Delta$ ") between points " $B$ " and "C" (Figure 1).

As shown in Figure 2 for representative subjects and in Table 2 and Figure 2 for mean data, patients presented with significant steeper deoxi-Hb slope than controls $(\mathrm{P}<0.01)$. Moreover, while deoxi-Hb remained stable or even decreased during phase " 3 " in all but one control (i.e., null or negative " $\Delta$ "), there were systematic increases in deoxi-Hb in all patients $(P<0.05)$. Steeper deoxi-Hb-work rate slope was associated with lower peak work rate in patients $(r=-0.73 ; P=0.01)$.

Table 1. Resting and exercise characteristics of healthy controls and patients with heart failure.

\begin{tabular}{|c|c|c|}
\hline Variables & Controls $(n=10)$ & Heart failure $(n=10)$ \\
\hline \multicolumn{3}{|l|}{ Demographic/anthropometric } \\
\hline Age (year) & $61.5 \pm 9.3$ & $52.1 \pm 11.7$ \\
\hline Weight (kg) & $76.5 \pm 9.1$ & $72.0 \pm 16.4$ \\
\hline Height $(\mathrm{cm})$ & $168.7 \pm 5.3$ & $166.7 \pm 8.6$ \\
\hline Body mass index $\left(\mathrm{kg} / \mathrm{m}^{2}\right)$ & $27.0 \pm 3.0$ & $25.8 \pm 4.9$ \\
\hline \multicolumn{3}{|l|}{ Echocardiogram } \\
\hline Left ventricular ejection fraction (\%) & $59.7 \pm 18.7$ & $29.1 \pm 4.9^{*}$ \\
\hline \multicolumn{3}{|l|}{ Medication } \\
\hline Thiazide diuretics $(\mathrm{N})$ & - & 7 \\
\hline Spironolactone $(\mathrm{N})$ & - & 4 \\
\hline Digitalis $(\mathrm{N})$ & - & 5 \\
\hline Carvedilol (N) & - & 10 \\
\hline ACE Inhibitors/ AR blockers (N) & - & 10 \\
\hline \multicolumn{3}{|l|}{ Incremental exercise } \\
\hline Peak work rate $(\mathrm{W})$ & $141 \pm 28$ & $80 \pm 26^{*}$ \\
\hline Peak $\dot{\mathrm{VO}}_{2}(\mathrm{~mL} / \mathrm{min})$ & $1758 \pm 313$ & $1134 \pm 416^{*}$ \\
\hline Peak $\dot{\mathrm{VO}}{ }_{2}\left(\mathrm{~mL} \cdot \mathrm{min}^{-1} \cdot \mathrm{kg}^{-1}\right)$ & $23.1 \pm 3.8$ & $15.4 \pm 4.9^{\star}$ \\
\hline$\dot{\mathrm{V}} \mathrm{O}_{2} \mathrm{LT}(\mathrm{mL} / \mathrm{min})$ & $746 \pm 120$ & $634 \pm 153$ \\
\hline$\dot{\mathrm{V}} \mathrm{O}_{2}$-work rate slope $\left(\mathrm{mL} \cdot \mathrm{min}^{-1} \cdot \mathrm{W}^{-1}\right)$ & $10.5 \pm 0.8$ & $8.8 \pm 1.7^{*}$ \\
\hline Peak RER & $1.21 \pm 0.09$ & $1.04 \pm 0.16^{*}$ \\
\hline Peak $\dot{V} E / \dot{V} \mathrm{CO}_{2}$ & $34.3 \pm 5.4$ & $47.6 \pm 13.5^{*}$ \\
\hline Peak $\mathrm{P}_{\mathrm{ET}} \mathrm{CO}_{2}(\mathrm{mmHg})$ & $35.0 \pm 5.2$ & $27.1 \pm 10.5$ \\
\hline Peak HR (bpm) & $140 \pm 26$ & $131 \pm 15$ \\
\hline
\end{tabular}

Data are reported as means $\pm S D$ or frequency $(N)$. ACE: angiotensin-converting enzyme; AR: angiotensin receptor; $\dot{\mathrm{V}}_{2}$ : oxygen uptake; $\mathrm{LT}$ : lactate threshold; RER: gas exchange ratio; $\dot{\mathrm{VE}}$ : ventilation; $\dot{\mathrm{V}} \mathrm{CO}_{2}$ : carbon dioxide output; $\mathrm{P}_{\mathrm{ET}}$ : end-tidal partial pressure; $\mathrm{HR}$ heart rate. ${ }^{*} \mathrm{P}<0.05$ (unpaired $t$-test). 


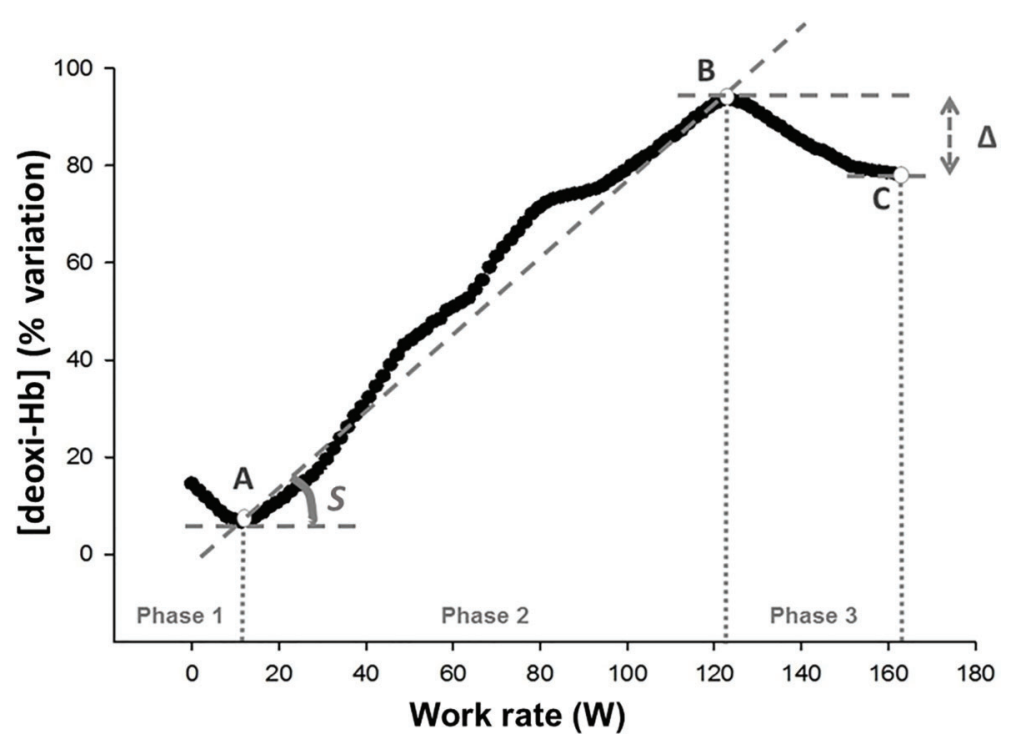

Figure 1. Representative deoxygenated hemoglobin concentration (deoxi-Hb) response profile (\% rest-peak variation) as a function of increasing exercise intensity in a healthy control. Points " $A$ " and " $B$ " correspond to the first and second inflection points. Point " $\mathrm{C}$ " is the peak work rate. In addition to the slope $(S)$ of deoxi-Hb increase throughout phase "2", deoxi-Hb difference between points " $\mathrm{B}$ " and " $\mathrm{C}$ " is depicted (" $\Delta$ ").

\section{Discussion}

This prospective study established a simplified approach to unravel abnormalities in peripheral muscle $\mathrm{O}_{2}$ delivery (i.e., lower blood flow in non-hypoxemic patients) as indicated by changes in NIRS-based deoxi-Hb during rampincremental cardiopulmonary exercise test in heart failure patients. Our results indicate that, compared to controls, patients presented with steeper mid-exercise slope of deoxi-Hb as a function of work rate coupled with lack of late-exercise stability (or even decreasing deoxi-Hb). We interpret these results as evidence of faster and higher $\mathrm{O}_{2}$ extraction to compensate for impaired convective and diffusive $\mathrm{O}_{2}$ flow to muscle mitochondria (10). This approach might prove useful to assess the effects of pharmacological and non-pharmacological methods aimed at improving intra-muscular microvascular hemodynamics in this patient population. The proposed approach can be easily applied in clinical settings, as it does not require data fitting with complex mathematical functions (7). Moreover, deoxi-Hb is reported as a function of work rate, and $\mathrm{V}_{2}$ measurements (i.e., cardiopulmonary exercise test) are not mandatory. Importantly, the proposed parameters (slope and " $\Delta$ ") are largely effort-independent, being recorded during submaximal exercise.

From a mechanistic standpoint, it has been long established that the key factors modulating $\mathrm{O}_{2}$ deliveryutilization matching in contracting appendicular muscles include: a) the muscle "pump" effect; b) local vasodilatation; c) parasympathetic and sympathetic tones, and d) differential patterns of muscle fiber recruitment, as reviewed by other authors $(4,10,19)$. Based on these premises, we interpreted the S-shaped pattern of muscle deoxygenation (deoxi-Hb) depicted in Figure 1 as indicating: a) an early phase ("1") in which proportional increases in $\mathrm{O}_{2}$ delivery and $\mathrm{O}_{2}$ requirements $\left(\dot{\mathrm{VO}}_{2}\right)$ led to a stable $\mathrm{O}_{2}$ extraction ( deoxi-Hb), b) a subsequent phase (" 2 ") in which deficits in $\mathrm{O}_{2}$ delivery relative to fast-increasing $\dot{\mathrm{V}}_{2}$ produced a marked increase in $\mathrm{O}_{2}$ extraction, and c) a final phase (" 3 ") in which $\mathrm{O}_{2}$ delivery and $\mathrm{O}_{2}$ requirements were once again matched leading to a stable rate of $\mathrm{O}_{2}$ extraction (or even decreasing if $\mathrm{O}_{2}$ delivery becomes excessive relative to instantaneous $\mathrm{O}_{2}$ needs) $(4,10)$. This model is consistent with previous contentions by Spencer et al (11), who found that the deoxi-Hb response profile during ramp-incremental exercise in healthy young males consisted of three distinct phases, in which the latter two were approximately linear, i.e., phases " 1 " and " 2 " herein described.

In this context, steeper phase " 2 " deoxi-Hb-work rate slope in patients than controls is strongly suggestive of impaired $\mathrm{O}_{2}$ delivery-utilization matching in the former group. It is noteworthy that these abnormalities occurred despite a shallower $\dot{\mathrm{VO}}_{2}$-work rate slope in patients. Thus, even if changes in $\mathrm{O}_{2}$ requirements were lower in patients, marked deficits in $\dot{Q}_{m}$ likely precluded a corresponding increase in $\mathrm{O}_{2}$ delivery. In other words, $\dot{\mathrm{V}}_{2}$ /extraction ratio was markedly reduced in patients, a finding consistent with impaired $\mathrm{O}_{2}$ delivery. Increased $\mathrm{O}_{2}$ extraction in patients might have also been influenced by lactacidosis-induced rightward shifts in the oxy-hemoglobin dissociation curve (Bohr effect) and/or greater recruitment of $\mathrm{O}_{2}$-costly type II fibers. Thus, a direct quantitative (inverse) relationship between $\dot{Q}_{m}$ and deoxi-Hb should not be attempted.

Progressive increase in late-exercise (phase " 3 ") deoxi$\mathrm{Hb}$ in patients, but not in controls, is another evidence of poorer muscle $\mathrm{O}_{2}$ delivery-utilization matching in heart failure conditions. In fact, there is growing evidence that despite progressive increases in work rate $\left(\right.$ and $\left.\dot{\mathrm{V}}_{2}\right)$, cardiac output might stabilize (or even decrease) near peak exercise in these patients (20-22). Microvascular perfusion-muscle 

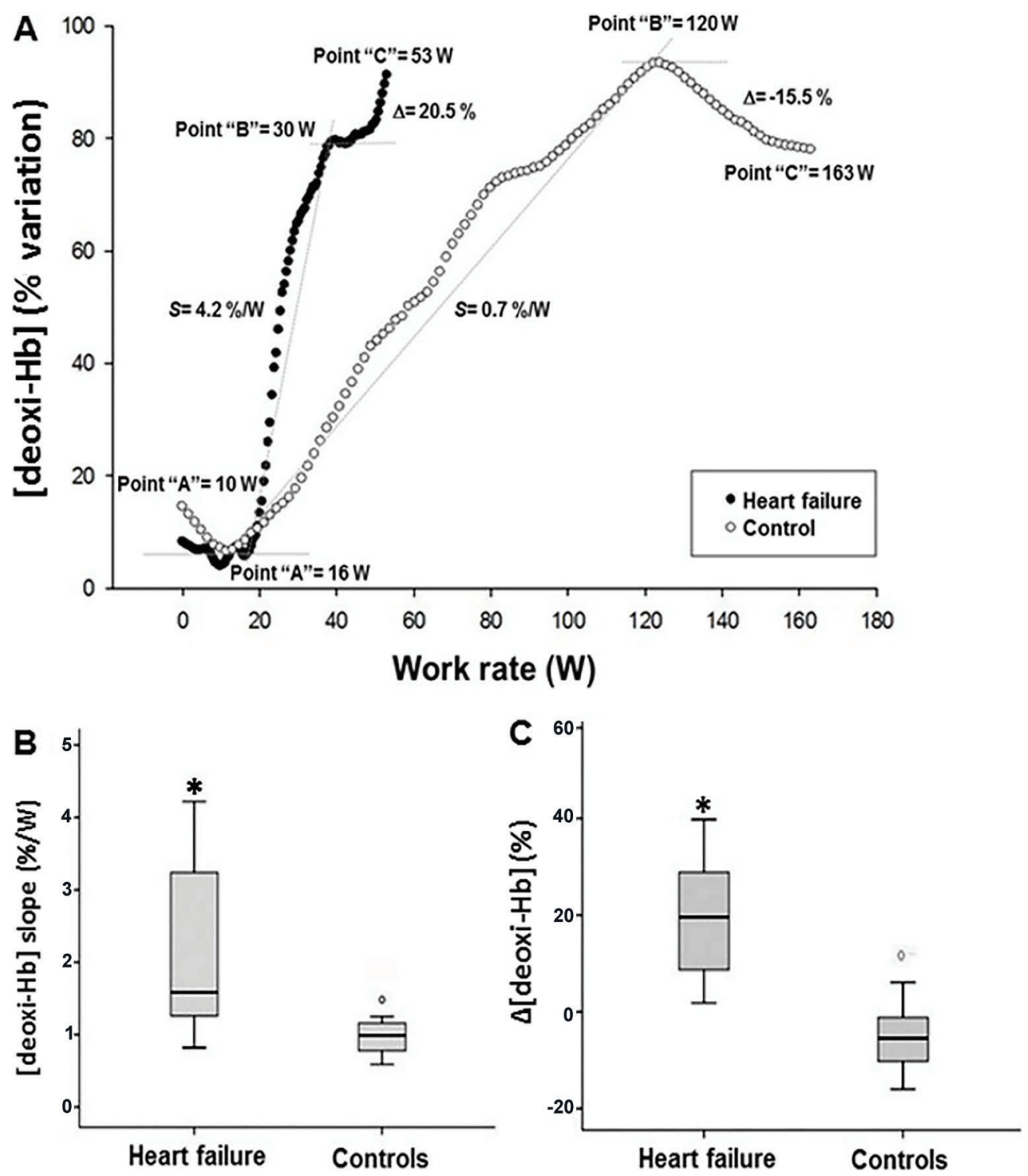

Figure 2. Representative deoxygenated hemoglobin concentration (deoxi-Hb) response profile (\% rest-peak variation) as a function of increasing exercise intensity in a representative control and a patient with heart failure (panel $A$ ). Lower panels show box plots comparing the slope of deoxi-Hb increase as a function of work rate throughout phase "2" (panel $B$ ) and $\Delta$ deoxi-Hb difference between points "B" and "C" (pane/ C). Data are reported as means \pm SD. Variables: [deoxi-Hb] Slope (S): Slope of the ratio [deoxi-Hb]/work-rate $(\%$ variation $/ \mathrm{W}) ; \Delta\left[\right.$ deoxi-Hb] $(\Delta)$ : variation of [deoxi-Hb] at the maximum work-rate point $(\mathrm{C})$ to the second inflection point $(\mathrm{B}) .{ }^{*} \mathrm{P}<0.05$ : Unpaired $t$-test (panel $B$ ) and Mann-Whitney test (panel $C$ ).

fiber recruitment uncoupling $(4,10,21)$ and sympathetic overexcitation (23) may also further impair $\dot{Q}_{m}$ near exercise termination. Moreover, type II fibers (with lower $\mathrm{ATP} / \mathrm{O}_{2}$ ratio) are mostly recruited at higher compared to lower work rates $(24,25)$, which might have contributed to muscle $\mathrm{O}_{2}$ delivery- $\mathrm{VO}_{2}$ mismatch in phase " 3 ".

As a noninvasive, cross-sectional study our investigation has some limitations that should be highlighted. We assume, as others $(5,8,26-28)$, that deoxi-Hb reflects muscle fractional $\mathrm{O}_{2}$ extraction $\left(\mathrm{C}(\mathrm{a}-\mathrm{v}) \mathrm{O}_{2}\right)$; however, we did not measure blood gas tensions. We also assumed that deoxi-Hb at a specific site gives a rough estimate of overall muscle $\mathrm{O}_{2}$ extraction $(8,14,16,28)$. Koga et al. (18), however, found large heterogeneity in $\dot{Q}_{m}-\dot{V}_{2}$ distribution in normal subjects, a phenomenon that might be more relevant for poorly perfused muscles. There is mounting evidence that $\dot{\mathrm{Q}}_{\mathrm{m}}-\mathrm{V}_{2}$ distribution abnormalities worsen as disease progresses in humans $(29,30)$ and animals $(31,32)$. Thus, our approach needs to be tested in more impaired patients. Finally, patients 
Table 2. Key variables of deoxygenated hemoglobin concentration (deoxi-Hb)work rate relationship in healthy controls and patients with heart failure.

\begin{tabular}{lcc}
\hline Variables & Controls $(\mathrm{n}=10)$ & Heart failure $(\mathrm{n}=10)$ \\
\hline Point "A" (W) & $19 \pm 14$ & $18 \pm 11$ \\
Point "B" (W) & $111 \pm 32$ & $53 \pm 19^{*}$ \\
[deoxy-Hb] slope $(\% / W)$ & $1.0 \pm 0.3$ & $2.2 \pm 1.3^{*}$ \\
$\Delta$ [deoxy-Hb] $(\%)$ & $-0.5 \pm 18.9$ & $20.3 \pm 12.9^{*}$ \\
\hline
\end{tabular}

Point "A": work rate after exercise onset at which deoxi-Hb started to increase; Point " $B$ ": work rate at which there was a systematic departure from linearity; [deoxi-Hb] Slope: slope of the ratio [deoxi-Hb]/work-rate (\%variation/W); $\Delta[$ deoxi$\mathrm{Hb}]$ : variation of [deoxi-Hb] at the maximum work-rate point $(\mathrm{C})$ to the second inflection point (B). Data are reported as mean $\pm \mathrm{SD}$. ${ }^{*} \mathrm{P}<0.05$ : unpaired $t$-test, except " $\Delta$ " (Mann-Whitney test).

performed a cycle ergometer test as the NIRS signal quickly deteriorates during fast walking; thus, our approach is unlikely to be feasible for treadmill-based tests.

In conclusion, we presented a practical approach to interpret the deoxi-Hb signal by NIRS during rampincremental cycle ergometry in heart failure patients. Impairments in $\mathrm{O}_{2}$ delivery, likely reflective of poor muscle blood flow in non-hypoxemic patients, were non-invasively uncovered by steeper mid-exercise slope of deoxi-Hb as a function of work rate and increasing (instead of stable or decreasing) deoxi-Hb near peak exercise. This novel strategy might prove useful to assess the effects of

\section{References}

1. Hirai DM, Musch TI, Poole DC. Exercise training in chronic heart failure: improving skeletal muscle $\mathrm{O} 2$ transport and utilization. Am J Physiol Heart Circ Physiol 2015; 309: H1419-H1439, doi: 10.1152/ajpheart.00469.2015.

2. Hunt SA, Abraham WT, Chin MH, Feldman AM, Francis GS, Ganiats TG, et al. ACC/AHA Guidelines for the diagnosis and management of heart failure in adults. J Am Coll Cardiol 2009; 53: e1-e90, doi: 10.1016/j.jacc.2008.11.013.

3. Wielenga RP, Coats AJS, Mosterd WL, Huisveld IA. The role of exercise training in chronic heart failure. Heart 1997; 78: 431-436, doi: 10.1136/hrt.78.5.431.

4. Boone J, Koppo K, Barstow TJ, Bouckaert J. Pattern of deoxy $[\mathrm{Hb}+\mathrm{Mb}]$ during ramp cycle exercise: influence of aerobic fitness status. Eur J Appl Physiol 2009; 105: 851-859, doi: 10.1007/s00421-008-0969-2.

5. Poole DC, Barstow TJ, McDonough P, Jones AM. Control of oxygen uptake during exercise. Med Sci Sports Exerc 2008; 40: 462-474, doi: 10.1249/MSS.0b013e31815ef29b.

6. Karavidas A, Arapi SM, Pyrgakis V, Adamopoulos S. Functional electrical stimulation of lower limbs in patients with chronic heart failure. Heart Fail Rev 2010; 15: 567-579, doi: 10.1007/s10741-010-9171-9.

7. Sperandio PA, Oliveira MF, Rodrigues MK, Berton DC, Treptow E, Nery LE et al. Sildenafil improves microvascular $\mathrm{O}_{2}$ delivery-to-utilization matching and accelerates exercise pharmacological and non-pharmacological interventions aimed at improving skeletal muscle perfusion in this patient population.

\section{Acknowledgements}

The authors thank all colleagues from the Pulmonary Function and Clinical Exercise Physiology Unit, Federal University of São Paulo (UNIFESP), Brazil for friendly collaboration. This study was supported by the Coordenação de Aperfeiçoamento de Pessoal de Nível Superior (CAPES), Brazil.
$\mathrm{O}_{2}$ uptake kinetics in chronic heart failure. Am J Physiol Heart Circ Physiol 2012; 303: H1474-H1480, doi: 10.1152/ ajpheart.00435.2012.

8. Ferreira LF, Townsend DK, Lutjemeier BJ, Barstow TJ. Muscle capillary blood flow kinetics estimated from pulmonary $\mathrm{O} 2$ uptake and near-infrared spectroscopy. J Appl Physiol 2005; 98: 1820-1828, doi: 10.1152/japplphysiol. 00907.2004.

9. Ferrari M, Mottola L, Quaresima V. Principles, techniques, and limitations of near infrared spectroscopy. Can J Appl Physiol 2004; 29: 463-487, doi: 10.1139/h04-031.

10. Ferreira LF, Koga S, Barstow TJ. Dynamics of noninvasively estimated microvascular $\mathrm{O}_{2}$ extraction during ramp exercise. J Appl Physiol 2007; 103: 1999-2004, doi: 10.1152/jappl physiol.01414.2006.

11. Spencer MD, Murias JM, Paterson $\mathrm{DH}$. Characterizing the profile of muscle deoxygenation during ramp incremental exercise in young men. Eur J Appl Physiol 2012; 112: 33493360, doi: 10.1007/s00421-012-2323-y.

12. Boone J, Bouckaert J, Barstow TJ, Bourgois J. Influence of priming exercise on muscle deoxy[Hb $+\mathrm{Mb}]$ during ramp cycle exercise. Eur J Appl Physiol 2011; 112: 1143-1152, doi: 10.1007/s00421-011-2068-z.

13. Neder JA, Nery LE, Castelo A, Andreoni S, Lerario MC, Sachs A, et al. Prediction of metabolic and cardiopulmonary 
responses to maximum cycle ergometry: a randomised study. Eur Respir J 1999; 14: 1304-1313, doi: 10.1183/ 09031936.99.14613049.

14. Grassi B, Pogliaghi S, Rampichini S, Quaresima V, Ferrari $\mathrm{M}$, Marconi $\mathrm{C}$, et al. Muscle oxygenation and pulmonary gas exchange kinetics during cycling exercise on-transitions in humans. J Appl Physiol 2003; 95: 149-158, doi: 10.1152/ japplphysiol.00695.2002.

15. Boushel R, Langberg $H$, Olesen J, Gonzales-Alonzo J, Bulow J, Kjaer M. Monitoring tissue oxygen availability with near infrared spectroscopy (NIRS) in health and disease. Scand J Med Sci Sports 2001; 11: 213-222, doi: 10.1034/ j.1600-0838.2001.110404.x.

16. Ferreira LF, Poole DC, Barstow TJ. Muscle blood flow-O2 uptake interaction and their relation to on-exercise dynamics of O2 exchange. Respir Physiol Neurobiol 2005; 147: 91103, doi: 10.1016/j.resp.2005.02.002.

17. Azevedo D, Medeiros WM, de Freitas FF, Ferreira Amorim C, Gimenes AC, Neder JA et al. High oxygen extraction and slow recovery of muscle deoxygenation kinetics after neuromuscular electrical stimulation in COPD patients. Eur $J$ Appl Physiol 2016; 116: 1899-1910, doi: 10.1007/s00421016-3442-7.

18. Koga S, Poole DC, Ferreira LF, Whipp BJ, Kondo N, Saitoh T, et al. Spatial heterogeneity of quadriceps muscle deoxygenation kinetics during cycle exercise. J Appl Physiol 2007; 103: 2049-2056, doi: 10.1152/japplphysiol.00627.2007.

19. Hirai DM, Copp SW, Holdsworth CT, Ferguson SK, McCullough DJ, Behnke BJ, et al. Skeletal muscle microvascular oxygenation dynamics in heart failure: exercise training and nitric oxide-mediated function. Am J Physiol Heart Circ Physiol 2014; 306: H690-H698, doi: 10.1152/ ajpheart.00901.2013.

20. Tanabe $Y$, Nakagawa I, Ito E, Suzuki K. Hemodynamic basis of the reduced oxygen uptake relative to work rate during incremental exercise in patients with chronic heart failure. Int J Cardiol 2002; 83: 57-62, doi: 10.1016/S0167-5273(02) 00013-X.

21. McDonough P, Behnke BJ, Padilla DJ, Musch TI, Poole DC. Control of microvascular oxygen pressures in rat muscles comprised of different fibre types. J Physiol 2005; 563: 903913, doi: 10.1113/jphysiol.2004.079533.

22. Rolim NP, Mattos KC, Brum PC, Baldo MV, Middlekauff $H R$, Negrão CE. The decreased oxygen uptake during progressive exercise in ischemia-induced heart failure is due to reduced cardiac output rate. Braz J Med Biol Res 2006; 39: 297-304, doi: 10.1590/S0100-879X2006000200018.

23. Ferreira LF, McDonough, Behnke BJ, Musc TI, Poole DC. Blood flow and $\mathrm{O} 2$ extraction as a function of $\mathrm{O} 2$ uptake in muscles composed of different fiber types. Respir Physiol Neurobiol 2006; 153: 237-249, doi: 10.1016/j.resp.2005. 11.004.

24. Krustrup P, Söderlund K, Mohr M, Bangsbo J. The slow component of oxygen uptake during intense, sub-maximal exercise in man is associated with additional fibre recruitment. Eur J Physiol 2004; 447: 855-866, doi: 10.1007/s00424003-1203-z.

25. Boone J, Koppo K, Barstow TJ, Bouckaert J. Aerobic fitness, muscle efficiency, and motor unit recruitment during ramp exercise. Med Sci Sports Exerc 2010; 42: 402-408, doi: 10.1249/MSS.0b013e3181b0f2e2.

26. Bauer TA, Reusch JE, Levi M, Regensteiner JG. Skeletal muscle deoxygenation after the onset of moderate exercise suggests slowed microvascular blood flow kinetics in type 2 diabetes. Diabetes Care 2007; 30: 2880-2885, doi: 10.2337/ dc07-0843.

27. Chiappa GR, Borghi-Silva A, Ferreira LF, Carrascosa C, Oliveira CC, Maia J, et al. Kinetics of muscle deoxygenation are accelerated at the onset of heavy-intensity exercise in patients with COPD: relationship to central cardiovascular dynamics. J Appl Physiol 2008; 104: 1341-1350, doi: 10.1152/ japplphysiol.01364.2007.

28. Sperandio PA, Borghi-Silva A, Barroco AC, Nery LE, Almeida DR, Neder A. Microvascular oxygen delivery-toutilization mismatch at the onset of heavy-intensity exercise in optimally treated patients with CHF. Am J Physiol Heart Circ Physiol 2009; 297: 1720-1728, doi: 10.1152/ajpheart.00596. 2009.

29. Lanfranconi F, Borrelli E, Ferri A, Porcelli S, Maccherini M, Chiavarelli $M$, et al. Noninvasive evaluation of skeletal muscle oxidative metabolism after heart transplant. Med Sci Sports Exerc 2006; 38: 1374-1383, doi: 10.1249/01.mss. 0000228943.62776 .69 .

30. Jendzjowsky NG, Tomczak CR, Lawrance R, Taylor DA, Tymchak WJ, Riess KJ, et al. Impaired pulmonary oxygen uptake kinetics and reduced peak aerobic power during small muscle mass exercise in heart transplant recipients. J Appl Physiol 2007; 103: 1722-1727, doi: 10.1152/japplphy siol.00725.2007

31. Diederich ER, Behnke BJ, McDonough P, Kindig CA, Barstow TJ, Poole DC, et al. Dynamics of microvascular oxygen partial pressure in contracting skeletal muscle of rats with chronic heart failure. Cardiovasc Res 2002; 56 : 479-486, doi: 10.1016/S0008-6363(02)00545-X.

32. Behnke BJ, Delp MD, Poole DC, Musch TI. Aging potentiates the effect of congestive heart failure on muscle microvascular oxygenation. J Appl Physiol 2007; 103: 17571763, doi: 10.1152/japplphysiol.00487.2007. 